\title{
LETTERS
}

Send your letters to the editor, British Dental Journal, 64 Wimpole Street, London W1G 8YS E-mailbdj@bda.org

Priority will be given to letters less than 500

words long. Authors must sign the letter,

which may be edited for reasons of space

\section{Crown distress}

Sir, I was distressed to read the paper by Threlfall et al. (BDJ 2005; 199: 453-455). The use of preformed crowns has been part of the armamentarium of dentists for more than half a century and should have been included in the curriculum in dental schools for most of that time. Several years ago the unpublished results of a small study carried out with GDPs showed that, when shown how, even totally inexperienced practitioners could fit and cement a preformed crown on a prepared tooth in 11 minutes.

The undoubted long-term success of these restorations was referred to and the technique necessary for their placement is far simpler and less critical than that for intra coronal restorations. If their use cannot be recommended for all children then they are certainly the technique of choice for co-operative children with extensive caries.

If preformed crowns are still not used it may be because in the dental schools the students are still not being adequately taught when and how to. This results in them having insufficient clinical experience and they therefore lack the confidence to carry out one of the less demanding techniques in the care of children.

\section{B. Scheer}

London

doi: 10.1038/sj.bdj.4813029

\section{NHS:private ratio}

Sir, I read with interest the Opinion paper After the first 125 years of the BDJ where might clinical dentistry be heading? by John Renshaw (BDJ 2005; 199: 331). He highlights the dilemma we, in the UK, face as a profession for the future: 'So what are we? Are we professional healthcare workers or are we now in the beauty trade? Should we be taking a dramatic vow of chastity?' In this paper the reality of disease distribution is identified in that the majority of the patients affected live in the poorer, deprived sectors of the community. It is also recognised that general medical practitioners have always been better paid by the NHS than dentists without any accusation of being 'gold diggers' and attributes this to the fact that society recognises doctors' efforts on behalf of the whole population.

Using Norway as an example, Grytten ${ }^{1}$ makes the point that increased costs for dental services are driven by the financing system in conjunction with imperfect competition. This has led to an increase in the capacity of dental education markedly so as to satisfy the demand for workforce. Grytten ${ }^{2}$ states: 'But this will lead to even more ineffectiveness in the dental market. More dentists will treat fewer patients, with higher fees. The experience from Norway illustrates the importance of looking at the financing system in relation to the employment situation and the training of dentists.'

In the UK we are about to embark on a new dental contract designed to reward dentists for applying twenty-first century principles of care based on the aims of dental health policy. However, there is dissatisfaction among general dental practitioners regarding this contract. This is understandable following the reported negotiations in the dental press and associated implementation delays. Also change in itself brings uncertainty.

If this dissatisfaction is translated into the loss of healthcare workers into the beauty trade then it is likely that there will be an expansion of what Downer ${ }^{3}$ terms 'unsupervised neglect' An alternative route is available to us as general dental practitioners and that is to embrace the new contract with the associated funding to facilitate access to the community and provide services based on need. In addition to this, we are able to use our clinical judgment to provide services based on patient desires within private agreements. The NHS:private ratio is likely to change as younger cohorts age, based on epidemiological evidence of disease trends. The number of patients requiring 'no dental intervention' has already increased by $10 \%$ over the last 10 years. ${ }^{4}$

This way we maintain our professional status and job security in the long term.

\section{W. Richards}

By email
1. Grytten J. Models for financing dental services. A Review. Comm Dent Health 2005; 22: 75-85.

2. Grytten J, Holst D. Fremtidig utdanningskapasitet for tannleger. Den norske Tannlegeforenings Tidende 2003; 113: 243-247

3. Downer M. Letters to the Editor. Models of financing dental services. A review. Comm Dent Health 2005; 22: 188-189.

4. Dental Practice Boards [http://www.dpb.nhs.uk/]

\section{doi: 10.1038/sj.bdj.4813030}

\section{Glucose advice}

Sir, an unusual piece of anecdotal evidence has recently been brought to light by our Oral Health Promotion team. That is, that some smoking cessation programmes are advocating the sucking of glucose tablets to aid in the control of craving for a cigarette. This is based on some published work by Robert West et al. ${ }^{1,2}$ Although the benefits of quitting smoking to both general and oral health are potentially huge, the use of glucose tablets taken at regular intervals throughout the day could have disastrous effects on the caries rate and experience of some individuals.

If this method of quitting is in fact a panacea then advice recommending patients to attend the dentist for regular/closer review than normal, along with recommending the use of a fluoride supplement (high fluoride toothpaste and/or fluoride mouthwash) should be given at the very least.

The HDA publication Helping smokers stop encourages the dental team to become involved in highlighting the oral health benefits of smoking cessation and to signpost patients considering quitting to the local smoking cessation service. As a profession we should also be engaging with our smoking cessation colleagues and forming a body of research which scientifically shows the benefit of using glucose tablets to aid quitting and balance that against a measured drop off in oral health of those involved, therefore obtaining evidence-based practice.

\section{R. Emanuel, T. Edwards}

\section{West Sussex}

1. West $R$ et al. Acute affects of glucose tablets on desire to smoke. Psychopharmacology 1999: 147: 319-321.

2. West R. Glucose for smoking cessation. Does it have a role? CNS Drugs 2001; 15: 261-265.

doi: $10.1038 /$ sj.bdj.4813031 


\section{Out-of-hours dental care}

Sir, I read the Department of Health's recent document NHS primary care dental services: Implementation of local commissioning with interest, in particular the intentions regarding out-of-hours dental care services. The document proposes that, from April 2006, PCTs will assume responsibility for the provision of out-of-hours dental services, and that provision of these services will no longer be a requirement under GDS contracts or PDS agreements. It is intended that out-ofhours dental services should be accessed by telephone (local helplines or NHS Direct) and subject to established triagealgorithms. With the exception of true dental emergencies (severe haemorrhage, threatened airway or overwhelming infection), treatment within 24-48 hours is indicated for the majority of dental conditions. It has been suggested that such conditions are best treated during open access sessions by local dentists during the working day. ${ }^{1}$ It would not be unreasonable to assume, therefore, that many people experiencing dental problems would seek earlier assistance/treatment from either their GP or from A\&tE.

I recently carried out a telephone survey of 30 randomly selected local GP practices to assess the current basic knowledge pertaining to the management and further referral of dental emergencies. From the results that I received I concluded that GPs do not receive sufficient training in the management of dental emergencies, nor are they sufficiently advised of available local dental services. Similar studies highlighted identical deficits in the dental knowledge of ActE SHOs. ${ }^{2,3}$ I am not suggesting that GPs should be expected to manage conditions requiring dental skills for which they have not received the necessary training, but that it would be advisable for them to be aware of the presentation of the most common oral complaints (aphthous ulceration, candidosis, dental abscesses, gingivitis and herpes simplex infections ${ }^{4}$ ) and where, by whom, and what form of treatment should be provided. This information is readily available on a website accessible to all GPs (www.prodigy.nhs.uk/guidance).

Accessing local dental services is often difficult. Although NHS Direct provides information and a degree of access it lacks the local knowledge to direct patients to the most appropriate dental service efficiently, or to provide up to date local information. Preston PCT plans to create a single point of contact for all local organisations, including GPs, and NHS Direct. This Dental Access Team (DAT) would operate at a local level, beneath
NHS Direct, collating local information regarding NHS dental services to produce a database of local dental provision.

Patients would then call the DAT, be asked a series of questions and be directed into Trust-based services (PDS and, currently, EDS) and local incentivised practices (GDS). Such questions, presented in the form of an algorithm, could be made available to GPs, who could then refer patients on to the relevant practices/services, or to review by a dentist, using the telephone numbers provided. This would help to ensure that patients can access NHS dental services appropriate to their needs.

\section{Storey}

\section{By email}

\section{Department of Health. Primary care dental services: Implementation of local commissioning. October 2005. Pennycook A, Makower R, Brewer A et al. The management of dental problems presenting to an Accident and Emergency department. $J R$ Soc Med 1993; 86: 702-703. \\ Patel K K, Driscoll P. Dental knowledge of Accident and Emergency Senior House Officers. Emerg Med J 2002; 19: 539-541. \\ Anderson R, Richmond S, Thomas D W. Patient presentation at medical practices with dental problems: An analysis of the 1996 General Practice Morbidity Database for Wales. Br Dent J 1999; 186: 702-703. Rouke S. Dental Public Health Project Manager, Dental Public Health, Cumbria and Lancashire.}

\section{doi: 10.1038/sj.bdj.4813032}

\section{Tennis ball treatment}

Sir, the treatment of airway restriction with dental appliances has recently become a fashionable topic. These can range from minor problems such as snoring to life threatening conditions such as sleep apnoea and several different forms of treatment have been recommended.

However, the condition is not well understood and consensus has by no means been reached on either the cause or the cure. This has not prevented a rapid increase in the number of courses encouraging dentists to increase their income by between £23,000 and £33,000 per year. I can imagine that for a focused clinician these claims may not be unrealistic, but should we not be looking more deeply into the cause and the longterm success of treatment?

There are many obvious natural factors associated with sleep apnoea including being overweight, sleeping on the back, leaving the mouth open especially when asleep and having a low muscle tone, all of which are also closely associated with modern lifestyles. Having worked with such patients since the 1980s, it is my belief that both snoring and sleep apnoea could almost be eliminated if sufferers could be taught to sleep on their side with their mouth closed, especially if in addition they could lose some weight and improve their muscle tone. The upper airway is rarely much of a problem and the open mouth posture is usually a habit rather than a need.

The special appliances that are recommended act somewhat empirically by holding the mandible forward and/or open to increase the pharyngeal airway. In a way they act like a functional appliance such as a Bionator but additional measures are sometimes recommended to prevent the patient dropping their jaw out of the appliance. Some do this by opening the bite wider and others by engaging both the upper and lower teeth.

It has been accepted for many years that functional appliances in general have a reciprocal effect on both the mandible and maxilla, reducing the overjet while lengthening the face. Simply put, the drag from the mandible pulls back the maxilla. Many clinicians believe that such changes are limited to children and that the adult facial skeleton is resistant to change, however recent research suggests that long-term wear of sleep apnoea appliances by adults also increases their facial height. ${ }^{1,2}$ Unfortunately this is exactly the opposite of what is required and must give rise to concern that after several years the resting airway would become smaller. This tendency must be all the greater if the upper and lower jaws are linked together.

There does not seem to be any evidence that these appliances are more effective than a tennis ball sewn into the back of the pyjamas.

\section{J. Mew}

By email

1. Bondemark L. Does two years nocturnal treatment with a mandibular advancement splint in adult patients with OSAS cause a change in the posture of the mandible? Amer J Orthod Dentof Orthoped 1999; 116: 621-628.

2. Robertson C, Herbison P, Harkness M. Dental and occlusal changes during mandibular advancement splint therapy in sleep disordered patients. Europ J Orthod 2003; 25: 371-376.

\section{doi: 10.1038/sj.bdj.4813033}

\section{A word of thanks}

Sir, I would like to express great appreciation to members of your association, Drs P. J. Russell, Barry J. Field and Denis Regan for donating audio visual equipment and books to the Department of Dentistry, College of Health Sciences of the University of Zimbabwe. The equipment and books will go a long way in assisting the training of dentists in this country.

The equipment and books were brought by Dr Hendrik de-Waal who recently visited our department.

Once again, thank you.

\section{M. Chidzonga}

Zimbabwe

doi: 10.1038/sj.bdj.4813034 